\title{
"SONO STRANIERO!" \\ TRABALHADORES ITALIANOS E AS RELAÇÕES \\ ENTRE IDENTIDADE NACIONAL E DE CLASSE NA \\ IMPRENSA OPERÁRIA EM SÃO PAULO (1920 E 1930)
}

Endrica Geraldo ${ }^{1}$

RESUMO: Este artigo pretende discutir como periódicos operários paulistanos que contavam com uma presença significativa de imigrantes italianos mobilizaram as relações tensas entre identidade nacional e identidade de classe no interior das lutas por direitos e melhores condições de trabalho. A análise está concentrada nas décadas de 1920 e 1930, período que recebeu menor atenção da historiografia em razão do progressivo declínio enfrentando pelas organizações operárias na região.

PALAVRAS-CHAVE: Imprensa operária. Imigrantes italianos. Identidades.

ABSTRACT: This article analyzes the relationship between national identity and class identity in working-class press, when there was a large presence of immigrants in São Paulo, especially Italian workers. This study discusses the press in the 1920s and 1930s, decades that has received less attention in historiography because of the progressive decline faced by workers' organizations.

KEYWORDS: Working-class press. Italian immigrants. Identities.

Professora Adjunta da Universidade Federal da Integração Latino-Americana (PR). Doutora em História. E-mail: endrica@gmail.com 
Desde as décadas finais do século XIX, os trabalhadores desenvolveram várias formas de articulação para enfrentarem as duras condições de trabalho e a crescente carestia em São Paulo. Nesse período, os imigrantes possuíam presença marcante entre os trabalhadores e também na formação do movimento operário paulistano, constituindo boa parte de suas lideranças. $O$ aumento do número de associações e o crescente desenvolvimento de uma imprensa operária causaram temores nas classes dominantes que se traduziram em iniciativas políticas de controle sobre esses indivíduos. A repressão assumiu caráter mais intenso nos períodos de maior atividade grevista, como nos anos de 1906 a 1908, 1912 a 1913 e, principalmente, de 1917 a 1921 (MARAM, 1979, p. 19 e 160; HALL, 2004, p. 259-260).

Nesse mesmo período, o nacionalismo constituiu um fenômeno internacional de intensa projeção, marcando a vida dos indivíduos em suas nações e, de forma mais complexa, a das populações migrantes pelo mundo. O presente artigo pretende discutir a participação de imigrantes italianos na elaboração de debates na crescente imprensa operária paulista, debates esses que mobilizaram elementos de identidade nacional e de classe. Uma parte significativa da discussão sobre as relações entre trabalhadores organizados, o processo migratório internacional e o crescimento do nacionalismo percorrem o período que vai do final do século XIX até a I Guerra Mundial. Este artigo procura avançar a discussão para os anos posteriores ao movimento grevista de 1917 no Brasil até meados da década de 1930, período marcado não apenas pelo declínio das organizações e mobilizações operárias, mas principalmente por um processo compreendido como de nacionalização dos trabalhadores no Brasil (TRENTO, 2010, p. 251).

Diante do desenvolvimento de estratégias destinadas a desmantelar o movimento operário no Brasil, os trabalhadores imigrantes estiveram bastante vulneráveis, em especial com a criação das primeiras leis e dispositivos republicanos que permitiam não apenas o fechamento de sindicatos por tempo indeterminado, como também possuíam como objetivo produzir uma base legal para a expulsão de militantes considerados 
como perturbadores da ordem social. (MENEZES, 1996, p. 95; BONFÁ, 2009, p. 183-215). As disputas e debates que cercaram as manifestações operárias e a elaboração de decretos destinados a garantir a ordem social na jovem República brasileira revelam o papel de destaque adquirido pela questão da identidade nacional naquele momento, e que assumiu significados e usos distintos por parte dos grupos em conflito.

Por um lado, a imprensa que se manifestava de forma contrária aos operários, utilizando como argumento a defesa da ordem, divulgava uma concepção de que os direitos reconhecidos aos cidadãos brasileiros não deveriam ser estendidos aos estrangeiros, para não beneficiarem, na expressão utilizada pelo Correio da Manhã no ano de 1917, os "hóspedes perigosos"2. A incorporação dos imigrantes à sociedade brasileira aparecia como atrelada à sua não participação nas crescentes lutas trabalhistas. A nacionalidade se tornou um elemento presente na imprensa de grande circulação, a qual responsabilizava os imigrantes pelas agitações operárias ao alegar que estes haviam trazido "na bagagem" ideologias "exóticas" como o anarquismo, o socialismo, o anarcossindicalismo, entre outros.

Em São Paulo, os trabalhadores italianos (assim como de outras nacionalidades) se depararam com a necessidade de enfrentar os significados e os usos da identidade nacional e do nacionalismo, recorrendo muitas vezes ao internacionalismo operário. Mas as formas pelas quais articularam elementos de identidade nacional e de classe foram bastante complexas no decorrer de todo o período denominado Primeira República. A partir da década de 1920, como veremos, outros elementos passaram a influenciar não apenas a composição da classe e do movimento operário em São Paulo, mas também os seus rumos e estratégias. Entre esses elementos constavam, por exemplo, a queda dos fluxos imigratórios, as novas estratégias de repressão e de controle social, o declínio do anarquismo e do anarcossindicalismo e a ascensão do regime fascista italiano.

2 HÓSPEDES perigosos. Correio da Manhã, Rio de Janeiro, p. 1, 18 set. 1917. 
A investigação sobre a relação entre a trajetória da migração italiana no mundo e o desenvolvimento do movimento operário nos países que os receberam contribui para a compreensão sobre como esses indivíduos construíram ou mobilizaram diferentes identidades juntamente com os trabalhadores ditos nativos. De acordo com Biondi, após a unificação da Itália, a considerável intensificação dos fluxos migratórios marcou profundamente o processo de construção de uma identidade nacional comum, sendo que as identidades múltiplas de muitos italianos se formaram fora da Itália. Biondi afirma não apenas a existência de um "conflito que muitos trabalhadores viveram na construção de suas identidades como italianos imigrados e ao mesmo tempo como trabalhadores", mas também o fato de que muitos desses indivíduos começaram a militar política ou sindicalmente no estrangeiro, especialmente antes da Primeira Guerra Mundial (BIONDI, 2000, p. 132-135).

Como um dos resultados do período de imigração em larga escala para o Brasil nas décadas finais do século XIX e início do século XX, Michael Hall destacou a predominância de imigrantes e seus descendentes na primeira classe operária paulistana. (HALL, 2004a, p. 260). Após 1896, a maioria dos imigrantes italianos que vieram para o Brasil se destinou a São Paulo. Até o ano de 1939, 944 mil italianos ingressaram apenas nesse Estado. Em 1920, de acordo com o censo, $71 \%$ dos italianos no país viviam em São Paulo (TRENTO, 2001, p. 102) ${ }^{3}$.

No começo do século XX, os italianos chegaram a $50 \%$ da população da cidade de São Paulo, onde só foram superados pelos portugueses em 1940 (HALL, 2004b, p. 124 e 128). Entre o final do século XIX e começo do XX, um número importante dos imigrantes italianos no Brasil era constituído por socialistas, anarcossindicalistas e anarquistas. Estes imigrantes

3 No entanto, a cifra de entradas de italianos no Brasil foi superada por outras nacionalidades como no período entre 1903 e 1919. Do total das entradas nesse período, $19 \%$ seriam de italianos, $21,9 \%$ de espanhóis e $36,9 \%$ de portugueses (TRENTO, 1989, p. 59). 
se concentravam em uma classe operária emergente em São Paulo e contribuíram no estabelecimento das primeiras uniões trabalhistas (TRENTO, 2001, p. 102). Para Trento, a imprensa anarquista de língua italiana proporcionou um importante ponto de partida para o processo de articulação dos trabalhadores em organizações revolucionárias baseadas na classe no interior de uma sociedade multirracial e multiétnica nos estágios iniciais da industrialização. Segundo o autor: "Dentre os radicais daqueles tempos, os anarquistas foram os mais hostis em relação aos Estados-Nações e seus projetos de construção nacional; seu internacionalismo era acentuado" (Ibid). É importante ressaltar, no entanto, que a imprensa operária denunciava o desinteresse de muitos imigrantes pelas reivindicações coletivas por estarem mais preocupados em alcançar o enriquecimento individual e a ascensão social. Michael Hall acredita que parte significativa dos imigrantes "encarou com ceticismo, se não com hostilidade, a possibilidade de sua participação em estratégias políticas baseadas em ação coletiva", além de demonstrarem grande desinteresse pela naturalização e por participação eleitoral (HALL, 2004b, p. 260-263).

Diferentes autores se referem à importância dos conflitos de classe como um elemento contrário ao crescimento de um sentimento de identificação ou de comunidade entre os italianos em São Paulo nas primeiras décadas do século XX. Enquanto empresários como Crespi e Matarazzo, por exemplo, procuraram fazer uso da questão étnica para minimizar as tensões com os operários, os jornais como o socialista Avanti os denunciavam como "exploradores patrióticos" (AVANTI!, 5 jan. 1901 apud TRENTO, 1989, p. 152-153). Trento argumento que as rivalidades regionais que os imigrantes traziam da Itália tornava difícil a busca por uma italianidade entre indivíduos para os quais "a Sicília estava tão distante quanto o Brasil, em termos culturais e lingüísticos". (Ibid.).

A historiografia que discute a formação da classe operária brasileira no final do século XIX e primeiras décadas do século XX tem demonstrado não apenas que a classe possuía uma 
composição bastante heterogênea, mas também como as divisões étnicas, políticas, por categorias e ofícios constituíram obstáculos importantes para as iniciativas que buscavam a organização dos trabalhadores no período (BATALHA, 2006, p. 166-168). Por um lado, os imigrantes impulsionaram o nascimento das organizações de classe e o desenvolvimento de reivindicações e protestos e, em São Paulo, os italianos constituíram a grande maioria das lideranças por quase três décadas. Mas as divisões entre trabalhadores nativos e estrangeiros e entre os próprios estrangeiros dificultaram a organização dos trabalhadores e o desenvolvimento de uma consciência de classe mais ampla. Entretanto, alguns fatores como o aumento da inflação e da jornada de trabalho e a piora nas condições de vida dos trabalhadores contribuíram para que muitas dessas divisões fossem superadas como durante o processo que resultou na eclosão da greve geral paulistana de $1917^{4}$. Além disso, os esforços anteriores realizados pelas associações e pela própria imprensa operária no sentido de superar as divisões internas da classe também contribuíram para a amplitude das mobilizações travadas nos anos entre 1917 e $1919^{5}$.

Há ainda outro elemento que merece ser destacado: naquele momento, muitos dos trabalhadores imigrantes acusados pelos militantes como mais interessados no enriquecimento pessoal e no retorno ao país de origem do que em conquistas coletivas de melhores condições de trabalho começavam a mudar de perspectiva. Uma parte considerável desses imigrantes passou a reconhecer as dificuldades em realizar esses objetivos individuais

4 Sobre o aumento da inflação, desemprego e pauperização dos trabalhadores e o agravamento da crise social no período que antecedeu o movimento grevista de 1917, ver: CAMPOS, 1988, p. 38-40 e LOPREATO, 2000, p. 73-84.

5 De acordo com Batalha, o impressionante aumento da criação de organizações operárias nas cidades do Rio de Janeiro e São Paulo no período entre 1917 e 1919 pode ser interpretado como indicação da instabilidade e do "caráter efêmero das sociedades operárias", mas também pode significar que "a despeito de condições adversas" que podiam levar ao fechamento das associações, "a cada conjuntura mais favorável, o operariado estava propenso a reconstituir e ampliar sua organização” (BATALHA, 2006, p. 172-173.). 
e abandonavam ou se distanciavam dos planos de retorno à nação de origem. Em relação aos imigrantes italianos, mais especificamente, houve praticamente uma paralisação dos fluxos internos (de imigrantes vindos das fazendas de café ou de regiões do sul do país à procura de ocupações urbanas) e externos para São Paulo, possibilitando uma estabilidade temporária de famílias que passavam a construir suas vidas nessa localidade sem planejar uma volta para a Itália. A estabilidade dos imigrantes italianos, que constituíam a grande parte dos trabalhadores de fábricas e oficinas em São Paulo, possuiu grande importância para o momento inicial da greve de $1917^{6}$.

Embora ofuscados pela presença intensa de anarquistas, de acordo com Biondi, os socialistas italianos foram bastante ativos e fundamentais no processo de reorganização das ligas sindicais. Além da refundação da Federação Operária de São Paulo (FOSP) em agosto de 1917, os sindicatos de bairro explicitavam "um novo momento organizativo de superação das diferenças étnicas, supranacional e brasileiro", mesmo que boa parte das ligas, principalmente as de ofício, continuasse apresentando "uma identidade de classe em muitos casos ainda com forte definição étnica". Além disso, os socialistas italianos moviam uma campanha para mostrar que os empresários italianos em São Paulo alcançavam um significativo enriquecimento e possuíam interesses na Grande Guerra. Os socialistas procuravam, por um lado, "contrastar o nacionalismo mais politicamente estruturado de alguns com o patriotismo popular" e, mais do que isso, combatiam intensamente o sistema de coleta de listas de subscrição que vinha sendo feita pelo Comitato Italiano Pro-Patria por meio de seus subcomitês de bairro ${ }^{7}$.

6 Este é o argumento de Biondi para questionar a interpretação de que esses eventos foram espontâneos, demonstrando uma organização complexa do movimento operário nesse período. A estabilização dos fluxos migratórios constitui, para o autor, um dos elementos responsáveis pela especificidade da greve paulistana de 1917 em relação aos movimentos anteriores, pois ela teria contribuído para um maior envolvimento dos imigrantes italianos na construção de organismos de defesa (BIONDI, 2009, p. 273-275; 288; 306).

7 Ibid., p. 271-277. 
Para Biondi, os socialistas exploraram o fato de que a arrecadação constituía um "fator de elevação da tensão interna nas fábricas paulistanas". Isto é, o enriquecimento dos empresários italianos contrastava com o empobrecimento dos trabalhadores e, assim, os próprios periódicos apontavam que o despertar do movimento operário, nesse momento, se iniciava com o pedido de abolição da taxa ${ }^{8}$.

Nesse período, entre os recursos utilizados pelos patrões e pelo Estado brasileiro para reprimir as agitações operárias, a presença de imigrantes no mercado de trabalho e especialmente no movimento operário foi particularmente explorada. A divulgação pela grande imprensa dos argumentos contrários às reivindicações operárias e que buscavam legitimar medidas repressivas como prisões, empastelamento dos jornais operários, deportações e a busca pela criação de decretos que legalizassem essas ações revelam a ênfase no caráter "estrangeiro" da mobilização operária.

Os discursos parlamentares e a imprensa de grande circulação representavam os trabalhadores "nacionais" como ingênuos que eram manipulados por líderes estrangeiros, adeptos de ideologias exóticas que não se adequavam à realidade nacional. A grande imprensa procurou, assim, alimentar as divisões entre trabalhadores nacionais e estrangeiros. O que chama a atenção, no entanto, é o significado atribuído ao termo "nacionais" nessas publicações. A condição da "nacionalidade" aparecia vinculada ao comportamento político e social do indivíduo e não ao lugar de nascimento, tempo de residência no país ou sequer ao processo de naturalização como, por exemplo, nos artigos "O problema dos indesejáveis" e "Os indesejáveis" publicados respectivamente no Correio da Manhã e O Paiz, ambos do Rio de Janeiro ${ }^{9}$.

8 Biondi cita o periódico anarquista paulistano Guerra Sociale e o socialista Avanti. Ibid., p. 279 e 283.

9 Ver, por exemplo: O PROBLEMA dos indesejáveis. Correio da Manhã, Rio de Janeiro, p. 1, 19 set 1917; e OS INDESEJÁVEIS. O Paiz, Rio de Janeiro, p. 1,19 set 1917. 
Contra esse argumento vinculado às ações repressivas, a imprensa operária respondeu com a defesa da solidariedade de classe e que os trabalhadores imigrantes deveriam ser tratados como brasileiros. Vários jornais denunciavam frequentemente que a repressão atingia os trabalhadores de forma geral: brasileiros e estrangeiros eram igualmente detidos pela polícia e os que não podiam ser deportados para fora do país, eram "deportados", dentro do país, para complexos prisionais como a Clevelândia. Essa imprensa denunciava que os ataques ao movimento operário ameaçavam as conquistas ou as lutas pelas melhorias nas condições de trabalho, e que, portanto, afetavam a todos os trabalhadores e não apenas aos imigrantes. A identidade nacional se tornou um tema presente nos argumentos de defesa e legitimação dos direitos que os trabalhadores, imigrantes ou brasileiros, deveriam possuir no país.

Vale lembrar, ainda, que desde a década de 1890 a língua da imprensa periódica no movimento operário paulistano era o italiano, fosse entre os anarquistas, socialistas ou sindicalistas. Por meio dessas publicações, imigrantes com maior experiência política procuravam sensibilizar os nativos e também seus conterrâneos sobre a questão social (BATALHA, 2006, p. 166168). A maioria eram jornais italianos com pelo menos uma seção em português (como L'Avvenire, La Barricata, Germinal, anarquistas, e o anarcossindicalista La Scure), mas também havia periódicos brasileiros com seções em italiano (como O Amigo do Povo, A lanterna, O Carpinteiro). Apenas a partir do final dos anos 1910 é que começa a diminuir o número de jornais italianos (TRENTO, 1989, p. 243).

A partir de 1917, alguns jornais publicados em São Paulo dedicaram uma atenção significativa aos debates sobre nacionalismo e sobre a presença de estrangeiros no movimento operário. Dentre os de língua italiana, podemos destacar os de caráter libertário como Alba Rossa, Germinal e Guerra Sociale, além do socialista Avanti e do antifascista La Difesa. Todos eles publicavam em italiano, possuíam seções em português e discutiam eventos relacionados aos trabalhadores no Brasil, mas 
também dedicavam muitos artigos para descrever o andamento de movimentos revolucionários em várias partes do mundo.

Em julho de 1917, o periódico Guerra Sociale, dirigido por Angelo Bandoni, comentava eventos recentes ocorridos no Rio de Janeiro, como greves, agitações a respeito de vítimas do desabamento do York-Hotel, a prisões de operários, proibição dos comícios, entre outros, que estariam causando polêmica também em grandes jornais. Sobre a ação da polícia no Rio, afirmava o periódico:

E o que é de notar especialmente nessa raiva Aureliana, são os processos soezes de calúnia e da mentira usados pelo chefe e seus subordinados. Aos jornais e aos tribunais, o sr. Aureliano informa, de face impassível, que as agitações operárias no Rio de Janeiro são fruto de meia dúzia de anarquistas estrangeiros, vagabundos e desalmados, quando sabe muito bem que os militantes de maiores responsabilidades no meio operário, entre nós, são brasileiros natos ou residentes no Brasil há dez, vinte e mais anos, trabalhadores, quase todos com família aqui constituída e com filhos aqui nascidos. (NO RIO - o chefe da mentira. Guerra Sociale, São Paulo, p. 4, 7 luglio 1917).

Dessa forma, o periódico apresentava a ideia de que a presença de brasileiros no movimento operário era significativa, com "as maiores responsabilidades", mas também procurava reforçar o argumento de defesa dos direitos constitucionais dos imigrantes residentes. Por essa razão, esses jornais, assim como os periódicos operários publicados em português como A Plebe e O Combate, destacavam as evidências - casamento com cônjuge brasileiro, filhos brasileiros, ou a residência há mais de cinco anos no país - de que esses imigrantes se enquadravam na categoria de residente, e, portanto, não poderiam ser deportados do Brasil ${ }^{10}$.

10 Procurei discutir os debates na imprensa sobre a questão da "residência" no artigo "Os prisioneiros do Benevente" (GERALDO, 2012). Sobre o assunto, ver também BONFÁ, 2009. 
Após as greves de 1917 foi fundado outro periódico de língua italiana em São Paulo, o libertário Alba Rossa. Criado em 1919 por Alessandro Cerchiai ${ }^{11}$, reunia militantes como Silvio Antonelli, Oreste Ristori e A. Bandoni e publicou 22 exemplares até outubro de 1919, quando afirmou que iria passar a apresentar contribuições em língua italiana para o periódico também libertário A Plebe, com o qual demonstrava ter forte articulação (AI NOSTRI lettori, Alba Rossa, São Paulo, p. 1, 13 ott. 1919) ${ }^{12}$.

O periódico demonstrou particular preocupação em confrontar as acusações de que as mobilizações e greves operárias eram causadas ou lideradas por indivíduos ou movimentos políticos estrangeiros. A partir de abril de 1919, Alba Rossa passou também a denunciar a manutenção de companheiros nas prisões em São Paulo e no Rio de Janeiro ao longo de meses (ALBA ROSSA. São Paulo, 12 apr. 1919, p. 2. $)^{13}$ e anunciava eventos como a "Festa Di Propaganda", para auxiliar A Plebe e companheiros presos. O evento seria constituído por algumas apresentações teatrais apresentadas em espanhol, como " $1^{\circ}$ de Maio" de Pedro Gori, e "Arlequin El Selvage", indicando o esforço para garantir a atração de imigrantes de outras nacionalidades (ALBA ROSSA, São Paulo, p. 3, 1 magg. 1919).

Em maio de 1919, um dos artigos dizia que existam rumores de que as mobilizações operárias daquele momento não estavam de fato relacionadas às causas econômicas verdadeiras, por

11 Cherchiai deixou a Itália após ter sido mantido preso durante dois anos por envolvimento em sublevações populares. Cherchiai chegou ao Brasil em 1901, foi para a Argentina em 1903, mas retornou ao Brasil em 1904 onde permaneceu, falecendo em 1935. Esteve envolvido na fundação, muitas vezes com apoio de outros militantes, de vários periódicos anarquistas como $\mathrm{La}$ Nuova Gente, La Barricata, La Propaganda, Guerra Sociale e Alba Rossa. Além disso, atou ainda como redator do La Battaglia entre 1904 e 1912. Ibid., p. 223-224.

12 Ao longo das décadas de 1920 e 1930, Alba Rossa foi publicado esporadicamente, em geral para a celebração do $1^{\circ}$ de maio.

13 Em abril, o periódico afirma que pretende aumentar a circulação de 1000 para 1500 cópias. ALBA ROSSA, São Paulo, p. 4, 16 febbr. 1919. 
serem promovidas por motivos políticos alheios aos interesses materiais dos grevistas:

É absolutamente falsa a afirmação que circula, segundo a qual se pretende fazer crer que o movimento atual é obra de hipotéticos elementos vindos do estrangeiro.

Que entre os trabalhadores em greve haja operários estrangeiros é uma coisa natural. As massas operárias são em grande parte constituídas por trabalhadores estrangeiros que dão seus esforços e a sua atividade para a nossa indústria.

As queixas dos operários foram claramente expostas e correspondem à necessidade local. Não há nada em comum entre as reivindicações de caráter estrangeiro e as aspirações econômicas do proletariado. (ALBA ROSSA. São Paulo, p. 1 e 4, 10 magg. 1919).

De acordo com o periódico, a presença de imigrantes na classe operária resultava na participação dos mesmos nas mobilizações grevistas, e as reivindicações do movimento constituíam consequência direta das condições locais em que viviam, ou seja, do alto grau de exploração dos trabalhadores nas relações de trabalho e do crescimento acintoso da inflação. Com isso, buscavam negar também que as greves ocorridas em 1919 representavam a ação ou a influência de movimentos estrangeiros ou da própria Revolução Russa. Entretanto, a mesma edição do periódico utilizava essa revolução como exemplo a ser seguido pelos trabalhadores em um artigo escrito em português:

Camaradas paulistas, estrangeiros e nacionais, pois que na luta pela igualdade não se distinguem nacionalidades, imitemos a Rússia, marchemos de fronte erguida e cheios de coragem para o porvir. (CAMARADAS [carta escrita em 3 de maio de 1919 por Antonio Pérez]. Alba Rossa, São Paulo, p. 4, 10 magg. 1919).

Alba Rossa assim confrontava a acusação de que os projetos políticos ou ideologias "estrangeiras" não constituíam as respostas para os problemas nacionais, defendendo a concepção de que 
os conflitos de classe constituíam uma realidade internacional. Diante dessa situação, os trabalhadores deveriam se unir, independentemente de sua origem nacional. Certamente, isso não impedia que essas afirmações fossem interpretadas ou apresentadas como evidências de influências externas sobre o movimento operário.

Os anos que se seguiram a essas greves foram marcados pelo aumento da repressão. Esses periódicos, por sua vez, investiram na defesa dos militantes e das reivindicações presentes em suas lutas. Em 1920, o periódico publicou um artigo intitulado "Sono Straniero!", associando algumas das suas reivindicações com a ironia quanto à acusação de que os anarquistas eram estrangeiros e eram também os grandes responsáveis pelas agitações sociais. Após descrever a aumento dos preços de alimentos, aluguéis e vestuário, afirmava que "a culpa dessa situação canibalesca, naturalmente, fica com os anarquistas que, além disso, são estrangeiros!...". O artigo apresentava o seu próprio autor da seguinte maneira:

Eu também sou um anarquista estrangeiro, desde que cheguei, pois fui trazido há 27 anos (eu tinha apenas 9) para esta terra hospitaleira, onde passei minha infância, juventude e quase a velhice, sempre e sempre trabalhando em circunstâncias difíceis, já que o trabalho neste país é mal pago e sem nenhuma garantia do direito dos trabalhadores, razão principal pela qual me tornei anarquista neste mesmo país. (SONO STRANIERO!. São Paulo, p. $2-3,1^{\circ}$ magg. 1920$) .{ }^{14}$

Mas não era apenas o tema da presença de imigrantes no movimento operário e da legitimidade de suas reivindicações que eram enfrentadas nas páginas de Alba Rossa. O periódico também denunciava violências policiais e as prisões de militantes. Mas seu foco principal constituía a apresentação de artigos sobre doutrina e sobre o andamento dos movimentos revolucionários em

${ }^{14}$ As traduções do italiano realizadas neste artigo são minhas. 
escala internacional. Surgido logo após o final da Primeira Grande Guerra, o periódico publicou vários artigos que relacionavam o conflito bélico como resultado do nacionalismo, definido como um fenômeno que mascarava a exploração dos trabalhadores pelas classes dirigentes e pelos governos. Contra as guerras e as nações, o periódico apresentava sua ênfase na defesa do internacionalismo operário (ALBA ROSSA. São Paulo, p. 1, 26 genn. 1919). Um dos argumentos apresentados em seus artigos era o de que os imigrantes também estavam entre as classes dirigentes e que estas procuravam utilizar o nacionalismo como uma estratégia de controle e exploração sobre os trabalhadores italianos no Brasil.

Em artigo escrito em português e assinado por Paulino Baci, o nacionalismo era acusado de constituir um instrumento utilizado pela burguesia capitalista para explorar os trabalhadores e que a "pátria" não garantia qualquer direito ou benefício aos trabalhadores, que morriam nas guerras em sua defesa:

Noticiaram os jornais que mais de vinte milhões de homens tombaram na horrenda carnificina que durante quatro anos e meio ensangüentou a humanidade.

São vinte milhões de pais, filhos, maridos e irmãos que nunca mais apertarão em seus braços os seres queridos.

São vinte milhões de braços que não mais se levantarão para pegar no arado ou na enxada. São vinte milhões de corações que deixaram de pulsar em peitos generosos e que derramaram seu precioso sangue em defesa da pátria.

Mas de qual pátria? Será em defesa do que ganharam com o seu trabalho?

Será em defesa do recanto de terra plantado e regado com o suor do seu rosto? (O PROLETARIADO e a Guerra. Alba Rossa, São Paulo, p. 2, 8 febbr. 1919).

De acordo com o artigo, a guerra respondia aos interesses dos "capitalistas e governantes" que, investindo no militarismo e na "paz armada", se beneficiavam por fazerem "fortuna em 
tempo de guerra, à custa do sacrifício do proletariado". Seriam sempre os próprios governantes e diplomatas que declaravam guerra e combinavam a paz, "sem consultar a vontade dos povos, massas de desconsiderados que têm de seguir sem protesto, para as linhas da frente, transformados em soldados para morrer sem saber o porquê". Os trabalhadores nada tinham a ganhar, ou mesmo a defender nos campos de batalha, mas eram eles que padeciam nos conflitos. Finalmente, quando as guerras se encerravam e esses indivíduos retornavam aos seus lares, o artigo questiona:

Quem Ihes dá trabalho e meios de sustento? O governo, a pátria? Muitas vezes, para não morrer de fome, sois obrigados a ir longe da pátria, procurar o trabalho ingrato.

Se a pátria não cuida e nada vale para os deserdados, se o governo só existe para oprimir as classes pobres, com que direito se chamam os proletários em defesa da pátria e das instituições? (Ibid. $)^{15}$.

O artigo podia assim lembrar a seus leitores as difíceis condições de vida que os obrigaram a deixar a Itália, afirmando que os trabalhadores e despossuídos não teriam qualquer razão para lutarem por qualquer pátria. A conclusão seria que os trabalhadores deviam ficar conscientes de que a "verdadeira guerra" que deviam enfrentar era contra a fome e devia ser travada por "todos os povos unidos contra o opressor". Alba Rossa denunciava a ação da polícia de Altino Arantes (São Paulo) e acusava o Fanfulla de contribuir com as críticas contra os anarquistas, acusando o jornalista Umberto Serpieri de realizar um jornalismo "pappatriótico"16 e reacionário (ALBA ROSSA. São Paulo, p. 3, 1 mar. 1919). O periódico manifestava apoio à Revolução Russa, acompanhado por severas críticas ao nacionalismo e ao patriotismo (IMPIARAMO. Alba Rossa, São

15 Ver também: L'ESERCITO. Alba Rossa, São Paulo, p. 2, $1^{\circ}$ magg. 1919.

16 O termo "pappatriótico" era utilizado na imprensa operária para ironizar o patriotismo italiano. 
Paulo, p. 1, 13 ott. 1919; PATRIOTISMO e Governo. Alba Rossa, São Paulo, p. 3-4, 31 genn. 1919).

Para promover a solidariedade da classe, essa imprensa operária de língua italiana investia no combate ao nacionalismo. Já no início de 1917, o periódico Guerra Sociale afirmava que o "último refúgio dos bandidos era o patriotismo". O periódico afirmava ter agido, juntamente com outros periódicos de língua italiana no Brasil, para combater o nacionalismo "nesses anos de entusiasmo patriótico, de entusiasmo canibalesco", reafirmando os princípios da Internacional (GUERRA SOCIALE, São Paulo, p. 3, 13 genn. 1917).

Mesmo após o combate às taxas do Comitato Italiano Pro-Patria em 1917, esses periódicos continuaram a discutir como o nacionalismo e a nacionalidade eram utilizados como instrumentos na exploração dos trabalhadores inclusive por empresários italianos. Entretanto, a partir da década de 1920 tanto a propaganda quanto a ação de classe passou a perder progressivamente a sua força em vários campos nos quais atuavam anteriormente. A queda do fluxo de imigrantes italianos e o envelhecimento dos ingressados anteriormente contribuíram para a perda progressiva da importância dos italianos entre as lideranças operárias paulistas, sendo que as migrações internas passam a crescer consideravelmente após 1929. A intensificação da repressão e a grave crise econômica internacional prejudicaram significativamente o movimento. A imprensa de classe foi bastante afetada, diminuindo drasticamente com a suspensão de vários jornais. As ligas de resistência entraram em crise e a presença de italianos entre as lideranças foi progressivamente substituída pelo elemento nativo. Ao longo desse processo, o movimento operário deixou de ser, como afirma Trento, "classificável por nacionalidades"17. A década de 1920 também veria surgir outro

17 Para o autor, a maior parte dos italianos naquele momento vivia no Brasil há muito anos, senão décadas, e os que ainda chegavam possuíam uma "sensibilidade política já formada" e eram convidados a participar de grupos e partidos brasileiros e a reforçar o movimento operário local. "Essa foi, sobretudo, a linha do partido comunista (que se fortaleceu também 
elemento que afetaria particularmente a vida desses trabalhadores no Brasil e os debates dos periódicos em questão: a ascensão do regime fascista na Itália.

Ao longo das décadas de 1920 e 1930, o regime fascista alcançou uma adesão importante na coletividade italiana no Brasil, mesmo entre os operários ${ }^{18}$. De acordo com Trento, a popularidade do regime fascista conseguiu conquistar uma população importante, principalmente na década de 1930, mesmo que isso estivesse mais relacionado ao grande prestígio que a Itália de Mussolini conseguiu conquistar no exterior do que de fato uma assimilação de linhas políticas e orientações ideológicas. A imagem positiva da Itália e do regime fascista entre a opinião pública nativa brasileira foi estimulada pela obra de propaganda feita tanto por representantes diplomáticos, quanto pelo cinema, pelos institutos ítalo-brasileiros de alta cultura, pela imprensa italiana e mesmo por demonstrações de simpatia presentes em jornais brasileiros. Além disso, a classe política local manifestava admiração pelo corporativismo, pelo modelo sindical, pelas relações com a Igreja e ainda pelas realizações da Itália fascista que eram divulgadas pela imprensa (TRENTO, 2010, p. 254).

A propaganda do regime fascista no Brasil foi particularmente favorecida por instituições e órgãos da coletividade imigrada. Mais do que os Fascios italianos no exterior, que contaram com um número baixo de membros no Brasil, os maiores sucessos foram alcançados pela ação do corpo diplomático e, principalmente,

com indicações provenientes da Terceira Internacional), linha que os correligionários italianos obrigados ao exílio não tiveram dificuldade em seguir, certamente por causa de sua irrelevância quantitativa, mas, acima de qualquer consideração, por causa de sua marginalidade dentro do antifascismo peninsular em São Paulo, que os levou a concentrar a própria atividade quase exclusivamente nas organizações de classe brasileiras". Trento, 2010, p. 250-251.

18 Para Trento, essa adesão pode ter tido um caráter superficial, "mas não há dúvida de que os próprios operários não pareceram se limitar a um indistinto fascismo 'genério'", questionando, portanto, o argumento apresentado por BERTONHA, 2010, p. 252. 
a "Opera Nazionale Dopolavoro"' [Organização Nacional dos Trabalhadores] - OND, com uma "abordagem menos direta e sob a cobertura de objetivos aparentemente apolíticos". As associações "Dopolavoro" possuíam uma série de recursos e estruturas para atrair associados e convidados e promoviam diversas atividades. As mais destacadas eram as de caráter esportivo, como torneios de futebol, basquete, vôlei, bocha, entre vários outros, e também com espetáculos teatrais e cinema. As OND constituíram um meio eficiente de penetração no proletariado e possuíram um alto grau de difusão no Brasil, que chegou a ser maior do que no resto dos países latino-americanos, e foram fundamentais para a socialização política das classes trabalhadoras (Ibid., p. 255258 e 262).

Ao longo desse período, a ascensão do fascismo passou a receber a atenção e as críticas dos operários de língua italiana em São Paulo. O periódico La Difesa promoveu diversas críticas contra o fascismo. Em 1927, divulgava a viajem de seu diretor, o jornalista socialista e antifascista Francesco Frola, para Juiz de Fora e Belo Horizonte, indicando o esforço dos militantes em promover o antifascismo também fora de São Paulo ( $L$ TRIONFALE accoglienza di Bello Horizonte all'on Frola. La Difesa, São Paulo, p. 1, 25 sett. 1927). O periódico denunciou a divulgação feita pelo Correio da Manhã, no Rio de Janeiro, de que o embaixador da Itália estava se movimentando no sentido de conseguir que o governo brasileiro expulsasse Frola, por sua ação contra o fascismo (LA DIFESA. São Paulo, p. 3, 18 dic. 1927). Em artigo publicado em português, o periódico La Difesa confrontou a denúncia feita por Romualdo Negrelli contra a vinda de Frola para o Brasil:

Pelo que vejo, a nacionalidade brasileira serve de esconderijo para acobertar um adepto do fascismo e atacar o jornalista Frola [...]. Lamenta-se o Sr. Negrelli que o sr. Frola tenha desembarcado no Brasil, e usando hipocritamente a máscara de brasileiro, diz que o Brasil tinha a obrigação de usar todas as precauções antes de lhe permitir a entrada. 
[...]

O Brasil, felizmente, não necessita dos conselhos interessados do último cav. acobertado com a máscara de brasileiro, e que no fundo não passa de um agente dos camisa preta, a instituição mais nefasta dos tempos modernos. (VIZZOTTO, Angelo. Poços de Caldas. La Difesa, São Paulo, p. 3, 28 nov. 1926.)

É possível perceber, nas palavras acima, como a defesa do militante de origem italiana foi realizada ao apontar o indivíduo com "máscara de brasileiro" que, na realidade, estaria atuando em benefício de um regime, este sim, estrangeiro. O periódico denuncia o uso excludente feito por Negrelli da questão da nacionalidade brasileira, que significaria que a atuação política de Frola no Brasil era indesejável e com presença ilegítima nas lutas operárias, mas, por outro lado, o periódico transferiu o peso de ser "estrangeiro" para o fascismo.

La Difesa atribuía grande destaque às ações fascistas em São Paulo em suas investidas contra militantes e imprensa antifascista ${ }^{19}$ e, em 1927, apresentou alguns balanços sobre os cinco anos do fascismo na Itália ${ }^{20}$. Mesmo durante a década de 1930, o periódico dedicou-se intensamente à propaganda antifascista, e procurava mesmo desqualificar Mussolini apresentando-o como um traidor dos movimentos operários, e que a campanha nacionalista movida por ele apenas camuflava a exploração dos trabalhadores. Por outro lado, essas denúncias não impediam que o próprio Frola interpretasse o fascismo como um regime "anti-italiano" e que os "exilados" é que representavam a nação italiana: "O fascismo não deve ser confundido com a Itália. É a Anti-Itália"21. Frola continua esse argumento, reforçando que o fascismo não era apenas "a

19 L'AZIONE provocatrice del Fascismo a San Paolo. La Difesa, São Paulo, p. 3, 25 dic. 1927; L'INDIPENDENZA della magistratura brasiliana. Ibid.

20 TURATI, Filippo. I - Cinque anni di fascismo. La Difesa, São Paulo, p. 2, 11 dic. 1927; II - La lezione rivoluzionaria del fascismo. Ibid.

21 FROLA, Francesco. I fuorusciti e l'Anti-Italia. La Difesa, São Paulo, p. 1, 11 nov. 1926. 
negação da pátria”, mas era também "a antítese de toda a tradição italiana", e as aspirações milenares "da nossa gente". Para o socialista, a Itália não era apenas uma palavra que se referia ao território, mas uma "alma, que vem de séculos de história, de tradições milenares, das aspirações constantes e nobres do seu povo" e o fascismo seria a própria destruição da obra dos grandes líderes da unificação italiana ${ }^{22}$.

Com relação ao nacionalismo fascista, também o periódico Alba Rossa expressava suas críticas, relacionando a ascensão do fascismo com os próprios heróis da unificação italiana, como na gravura a seguir:

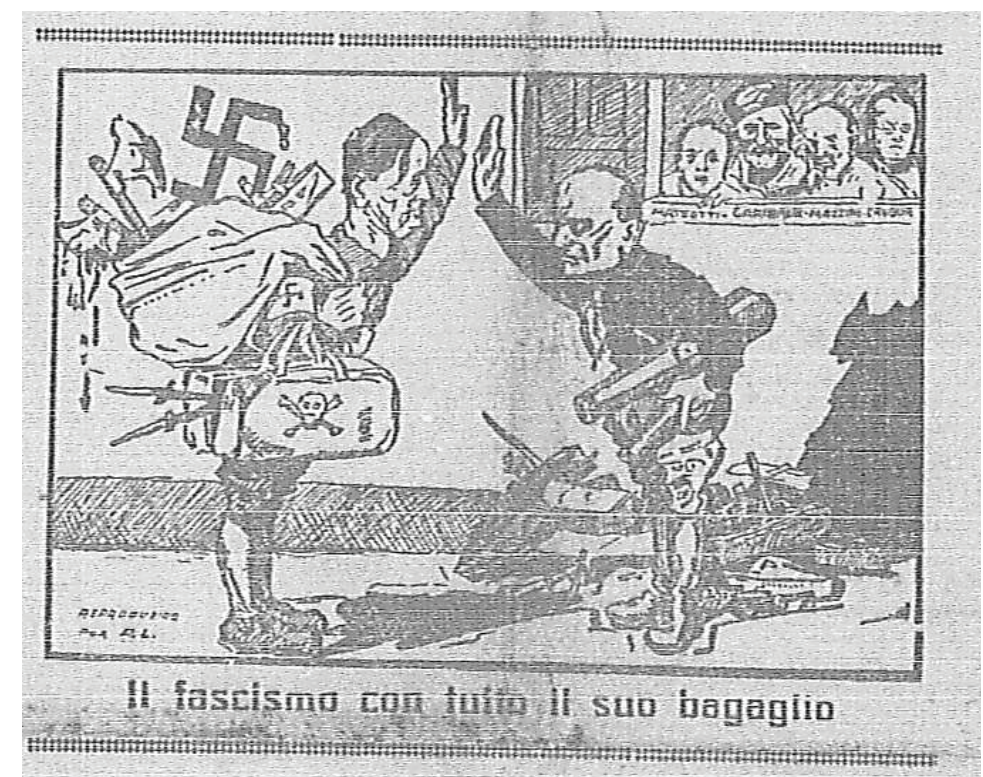

IL FASCISMO com tutto il suo bagàglio [O fascismo com toda a sua bagagem]. Alba Rossa, São Paulo, 7 luglio 1934, p. 1.

22 Id. II fascismo è l'anti-Italia - II fascismo è la negazione della pátria, non solo, ma è anche l'antitesi di tutta la tradizione italiana. La Difesa, São Paulo, p. 1, 28 nov. 1926. 
A imagem foi publicada em uma edição de 1934, mostrando uma saudação entre Hitler e Mussolini que carregam armas ensanguentadas e símbolos como a suástica nazista. Atrás de Mussolini, do outro lado de uma janela, observam a cena alguns dos principais personagens associados à luta contra o fascismo e ao processo de unificação italiana. O primeiro deles era Giácomo Matteotti, deputado socialista, assassinado em 1924 após apresentar denúncias no parlamento contra a manipulação fascista das eleições e, portanto, um dos grandes símbolos da luta contra o fascismo. Ao lado dele estavam Garibaldi, Mazzini, Cavour, símbolos da unificação italiana. Apesar das críticas ao nacionalismo fascista, em alguns momentos tanto La Difesa quanto Alba Rossa acabavam representando o regime fascista como uma violência contra a própria nação italiana. Em um contexto em que a classe e o movimento operário em São Paulo caminhavam no sentido de se tornarem cada vez mais "brasileiros", os periódicos militantes de língua italiana ainda mostravam uma complexa relação entre identidade nacional, identidade de classe e combate ao fascismo. Ao defenderem os direitos dos trabalhadores em suas páginas, os periódicos insistiam que os imigrantes deveriam ser tratados como "brasileiros". Ao combaterem o crescimento do fascismo na Itália e no Brasil, os jornais insistiam que o nacionalismo era um instrumento utilizado para camuflar a luta de classes. Mas, em vários momentos, expressavam a crença na existência de uma "verdadeira" Itália, representada pelos trabalhadores italianos espalhados pelo mundo, e ameaçada pela violência e autoritarismo do regime de Mussolini.

Embora esse confronto entre diferentes concepções de nação italiana tenha alcançado uma dimensão particularmente significativa nas décadas de 1920 e 1930, ele não constituía uma novidade. Na passagem do século XIX para o XX no Brasil, os republicanos italianos expressavam um conceito de uma nação proletária, e também de cidadania e identidade italiana, representada por seus emigrantes espalhados pelo mundo, mas especialmente nas Américas - "uma Itália potencialmente socialista e republicana" - contra a ideia de uma nação burguesa 
e monarquista, expressa pelos consulados e com o apoio dos "homens da elite da colônia, sobretudo os empresários e profissionais mais bem sucedidos"23. Posteriormente, portanto, esse inimigo da nação proletária passou a ser representado pelo fascismo.

\section{Conclusão}

Essa discussão compartilha o caminho percorrido pelos estudiosos da história do trabalho que tem investigado o processo pelo qual identidades étnicas e nacionais foram articuladas, às vezes associadas ou então confrontadas com outras identidades, como a de classe (ou ainda de gênero, religiosa, entre outras). Assim, os sujeitos históricos são considerados como portadores de identidades múltiplas que podem ser instrumentalizadas em momentos específicos. Ao analisar as relações entre etnicidade e classe em São Paulo, Michael Hall propõe que a etnicidade seja interpretada de forma semelhante à que $\mathrm{E}$. P. Thompson tratou o conceito de consciência de classe: "em vez de considerá-la como sempre igual e como uma entidade reificada que determina certas práticas, poderíamos tentar ver, no decorrer de lutas, como uma identificação étnica pode emergir (ou não), se desenvolver e esvaecer em circunstâncias históricas específicas" (HALL, 2010, p. 63).

A migração internacional podia tanto enfraquecer quanto incentivar o desenvolvimento de uma identidade nacional italiana. Redes internacionais de migração reforçavam a importância das vilas e regiões, deixando pouco incentivo para muitos camponeses, com seu tradicional ceticismo em relação aos Estados, para se transformarem rapidamente em nacionalistas italianos. ${ }^{24}$ Ao invés disso, muitos migrantes denominavam a

23 Para Biondi, esta era uma batalha também sobre "diferentes concepções de cidadania italiana, e portanto de identidade" (BIONDI, 2000, p. 136-137).

${ }^{24}$ Franzina destaca a percepção das classes dirigentes italianas quanto ao pouco apreço dos camponeses do Vêneto com relação à sua anexação à Itália. $\mathrm{O}$ autor cita um dos relatórios agrários datado de 20 anos após a anexação 
terra onde conseguiam sustento como sua verdadeira pátria ou que "nossa pátria é o mundo inteiro". Com base nesses elementos, Gabaccia sugere que seriam essas as razões para o grande desinteresse de migrantes italianos pela naturalização e ativismo eleitoral (GABACCIA, 1994, p. 73-75). Portanto, essa circulação global de milhões de trabalhadores e exilados políticos italianos teria propiciado uma significativa circulação de ideias, experiências e ideologias entre a Itália e as "Pequenas Itálias" espalhadas pelo mundo (GABACCIA, 1991, p. 111).

Em São Paulo, as disputas e debates que cercaram as manifestações operárias e a elaboração de decretos destinados a garantir a ordem social na jovem República brasileira revelam o papel adquirido pela questão da identidade nacional naquele momento, e que assumiu significados e usos distintos por parte dos grupos em conflito. Nessa imprensa operária, essas identidades foram mobilizadas ou enfrentadas na elaboração das lutas e das defesas de militantes presos ou ameaçados de expulsão. Os periódicos passaram a perder espaço progressivamente, mas continuaram a insistir que as estratégias de repressão afetavam pesadamente 0 militante estrangeiro, que se tornava alvo não apenas das expulsões, mas de uma série de medidas que passavam cada vez mais a excluílos das lideranças das associações e sindicatos ${ }^{25}$, e, finalmente, eram constantemente deslegitimados em suas reivindicações. Ao longo das décadas de 1920 e 1930, os periódicos enfrentavam essas questões e continuaram a promover a solidariedade da classe, ainda que o movimento não possuísse mais o vigor das décadas anteriores.

do Vêneto que afirmava: "o amor pela pátria é um sentimento totalmente desconhecido aos nossos vilões e a maior parte deles ainda têm saudade do domínio austríaco, sob o qual pagavam menos; eles se preocupam com uma coisa apenas, isto é, ter as menores cobranças possíveis, tanto do contrato com o patrão, quanto municipais, provinciais ou governativos" (FRANZINA, 2006, p. 305 e 317).

25 Como no Decreto no 19.482, de 12 de dezembro de 1930. In: BRASIL. [Leis etc.]. Coleção das Leis da República dos Estados Unidos do Brasil de 1930. Rio de Janeiro: Imprensa Nacional, 1931. V. II, Atos da Junta Governativa Provisória e do Governo Provisório (outubro a dezembro). 
O surgimento do fascismo e a ação das Dopolavoro no Brasil contribuíram para complicar ainda mais as relações entre classe e identidade nacional, e provavelmente para fortalecer a última em detrimento da primeira. O fascismo, o declínio das correntes anarquistas e anarcossindicalitas no movimento operário paulistano e a queda dos fluxos imigratórios contribuíram para que os italianos fossem assimilados com os trabalhadores nativos, fazendo com que os italianos progressivamente perdessem sua especificidade étnica no interior do movimento operário em São Paulo.

\section{Referências}

BATALHA, Cláudio H. M. Formação da classe operária e projetos de identidade coletiva. In: FERREIRA, Jorge; DELGADO, Lucilia de A. N. (Orgs.). O tempo do liberalismo excludente: da Proclamação da República à Revolução de 1930. Rio de Janeiro: Civilização Brasileira, 2006.

BERTONHA, J. F. O fascismo e os imigrantes italianos no Brasil. Porto Alegre, RS: EDIPUCRS, 2001.

BIONDI, Luigi. A greve geral de 1917 em São Paulo e a imigração italiana: novas perspectivas. Cadernos AEL, Campinas, v. 15, n. 27, p. 259-307, 2009.

BIONDI, Luigi. Identidade de classe e identidade nacional entre solidariedade e conflito: socialistas e republicanos na São Paulo do início do século $\mathrm{XX}$ e suas relações com as associações patrícias e o nascente sindicalismo. Estudos Ibero-Americanos, Porto Alegre, v. XXVI, n. 1, p. 131-162, jul. 2000.

BONFÁ, Rogério L. G. "Com lei ou sem lei”: as expulsões de estrangeiros na Primeira República. Cadernos AEL, Campinas, v. 14, n. 26, p. 183215, 2009. 
CAMPOS, Cristina H. O sonhar libertário: movimento operário nos anos de 1917 a 1921. Campinas: Editora da Unicamp, 1988.

FRANZINA, Emilio. A grande emigração: o êxodo dos italianos do Vêneto para o Brasil. Campinas, SP: Editora da Unicamp, 2006.

GABACCIA, Donna R. "Wherever we work, that land is ours": The Italian anarchist press and Working-Class solidarity in São Paulo. In: GABACCIA, Donna R.; OTTANELLI, Fraser M. Italians workers of the World: labor migration and the formation of multiethnic states. Urbana: Univ. of Illinois, 2001. p. 102-120.

GABACCIA, Donna R. Worker Internationalism and Italian Labor Migration, 1870-1914. International Labor and Working-Class History, New York, n. 45, p. 63-79, 1994.

GABACCIA, Donna R. American Studies Association: Internacionalism and the U.S. Working Class. International Labor and Working-Class History, New York, n. 40, p. 111-112, 1991.

GERALDO, Endrica. Os prisioneiros do Benevente. Revista Brasileira de História, São Paulo, v. 32, n. 64, p. 61-76, 2012.

HALL, Michael M. Entre a etnicidade e a classe em São Paulo. In: CARNEIRO, M. L. T.; CROCI, F.; FRANZINA, E. (Orgs.). História do trabalho e histórias da imigração: trabalhadores italianos e sindicatos no Brasil (séculos XIX e XX). São Paulo: Editora da Universidade de São Paulo; Fapesp, 2010.

HALL, Michael M. Imigrantes na cidade de São Paulo. In: PORTA, Paula (Org.). História da Cidade de São Paulo. São Paulo: Paz e Terra, 2004a. v. 3.

HALL, Michael M. O movimento operário na cidade de São Paulo, 18901954. In: PORTA, Paula (Org.). História da cidade de São Paulo. São Paulo: Paz e Terra, 2004b. v. 3. 
LOPREATO, Christina R. O espírito da revolta: a greve geral anarquista de 1917. São Paulo: Annablume, 2000.

MARAM, Sheldon L. Anarquistas, imigrantes e o movimento operário brasileiro, 1890-1920. Rio de Janeiro: Paz e Terra, 1979.

MENEZES, Lená Medeiros de. Os indesejáveis: desclassificados da modernidade. Protesto, crime e expulsão na Capital Federal (1890-1930). Rio de Janeiro: Editora da UERJ, 1996.

TRENTO, Angelo. Organização operária e organização do tempo livre entre os imigrantes italianos em São Paulo (1889-1945). In: CARNEIRO, M. L. T.; CROCI, F.; FRANZINAE. (orgs.). História do trabalho e histórias da imigração: trabalhadores italianos e sindicatos no Brasil (séculos XIX e XX). São Paulo: Editora da Universidade de São Paulo; FAPESP, 2010.

TRENTO, Angelo. Do outro lado do Atlântico: um século de imigração italiana no Brasil. São Paulo: Studio Nobel, 1989.

Recebido em julho de 2016. Aprovado em janeiro de 2017. 